\title{
Scimitar sign with normal pulmonary venous drainage and anomalous inferior vena cava
}

\author{
B HERER, F JAUBERT, C DELAISEMENTS, G HUCHON, J CHRETIEN \\ From the Clinique de Pneumo-Phtisiologie, Université René Descartes, Hôpital Laennec, Paris, France
}

ABSTRACT A case of the scimitar sign due to an anomaly of the right sided pulmonary vein with normal drainage into the left atrium was associated with an azygos continuation of the inferior vena cava. Digital subtraction angiography allows the identification of these rare congenital vascular malformations.

The "scimitar syndrome" is a combination of a hypoplastic right lung, dextrocardia, and anomalous right sided pulmonary venous drainage into the inferior vena cava. It produces a curved vascular shadow along the right heart border on the chest radiograph, the scimitar sign.' We report a case in which the scimitar sign was due to an anomaly of the right pulmonary vein with normal drainage into the left atrium. This malformation was associated with an anomalous systemic venous drainage without evident cardiac abnormality. A similar syndrome has not been described previously.

\section{Case report}

A 48 year old non-smoking woman was referred for investigation of an abnormal chest radiograph and a history of mild dyspnoea of recent onset with an occasional unproductive cough. She had no past history of cardiac or pulmonary disease and no known personal or family history of congenital malformations. She had five healthy children and was herself the product of a normal pregnancy.

Physical examination showed a healthy looking woman with no cyanosis or finger clubbing. The thorax was symmetrical, the heart sounds were normal, and the breath sounds were vesicular. The rest of the clinical examination showed nothing abnormal. The electrocardiograph and results of lung function tests were normal. Arterial blood gas values were: an oxygen tension $\left(\mathrm{PO}_{2}\right)$ of $12.4 \mathrm{kPa}$, a carbon dioxide tension $\left(\mathrm{PCO}_{2}\right) 5 \cdot 2 \mathrm{kPa}$, and $\mathrm{pH} \mathrm{7.36}$. A chest radiograph disclosed a scimitar sign as a curvilinear vascular shadow running parallel to the right heart border (fig 1). Pulmonary scintigraphy showed a substantial decrease in perfusion of the right lung. Echocardiography showed nothing abnormal.

A conventional angiogram via the right femoral vein disclosed an infrahepatic interruption of the inferior vena cava with an azygos vein continuation. The supradiaphragmatic examination was non-contributory owing to incom-

Address for reprint requests: Dr B Herer, Hôpital Laennec, 42 rue de Sèvres, F-75040 Paris, France. plete opacification. A digital subtraction angiogram was performed via an antecubital vein to define the scimitar sign and then via the right femoral vein to ascertain the anomalous systemic venous return. The first part of this examination showed that the upper right main pulmonary vein drained into a large vein that descended to the dia-

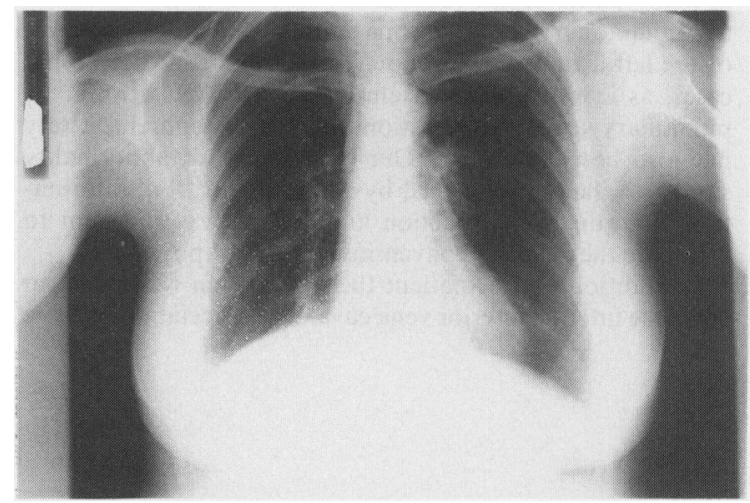

Fig 1 Original chest radiograph of the patient showing the scimitar sign.

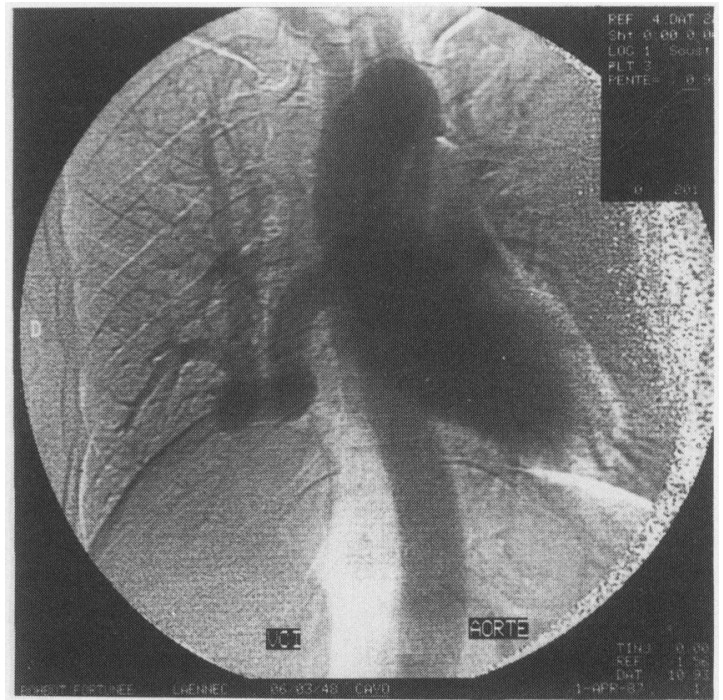

Fig 2 Digital subtraction angiogram showing a large pulmonary vein descending to the diaphragm and making a sharp turn to drain into the left atrium. 
phragm and then made a sharp turn upwards to drain completely into the left atrium (fig 2). No pulmonary arteriovenous fistula was detected. The second part of the examination confirmed the infrahepatic interruption of the inferior vena cava with an azygos continuation.

\section{Discussion}

The presence of a scimitar sign is attributable here to an abnormally large pulmonary vein draining normally into the left atrium. The scimitar sign is usually seen as part of the scimitar syndrome. The syndrome is characterised by anomalous right sided pulmonary venous drainage into the inferior vena cava in association with other anomalies, mainly right lung hypoplasia, dextrocardia, and abnormal bronchopulmonary segmentation or other abnormal vascular connections.' The scimitar sign may, however, be seen in many pathological conditions-for example, anomalous right pulmonary venous drainage to the superior vena cava ${ }^{2}$ or the left atrium and inferior vena cava, ${ }^{3}$ or in exceptional cases, as in our patient, exclusively to the left atrium. ${ }^{4} \mathrm{~A}$ pulmonary vessel sequestration by a right subphrenic artery has also been described. ${ }^{5}$ Our case shows an abnormality similar to the one described by Morgan et al, ${ }^{4}$ but information from digital subtraction angiograms was sufficient to eliminate the need for conventional angiography.

In addition, in our patient the azygos vein was found to continue into the inferior vena cava. The association of these two unusual vascular malformations in the same patient has $\overrightarrow{\bar{F}}$ not, to our knowledge, been described. Although it could be a coincidental occurrence, our observation suggests that aㄷ single event during fetal development was the origin of this $\underline{\bar{O}}$ dual vascular malformation." Digital subtraction angio- $\frac{\bar{\sigma}}{\sigma}$ graphy could be useful in the search of associated systemic $\overparen{\mathbb{D}}$ venous abnormalities in cases of anomalous pulmonary venous drainage.

\section{References}

1 Farnsworth AE, Ankeney JL. The spectrum of scimitar syndrome. J Thorac Cardiovasc Surg 1974;68:37-42.

2 Sutherland RD, Korns ME, Pyle RR. Intrapulmonary vein contributing a segment of venous supply to contralateral lung. Chest 1970;57:182-4.

3 Gazzaniga AS, Matloff JM, Harken DE. Anomalous right pulmonary venous drainage into the inferior vena cava and left $\rightarrow$ atrium. J Thorac Cardiovasc Surg 1969;57:251-4.

4 Morgan JR, Forker AD. Syndrome of hypoplasia of the right lung and dextroposition of the heart: "scimitar sign" with normal pulmonary venous drainage. Circulation 1971;43:27-30.

5 Khalife K, Sadoul N, Fays J, Simon P, Gilgenkrantz J, Lamy P. Le signe du cimeterre: veine pulmonaire ou artère systémique? A c propos d'un cas de séquestration vasculaire pure. Rev Pneumol Clin 1985;41:410-2.

6 Clark EB, Martini DR, Rosenquist GC. Spectrum of pulmonary $\infty$ venous connections following ling bud inversion in the chick embryo. In: Pexieder T, ed. Perspectives in cardiovascular research. Vol 5. Mechanisms of cardiac morphogenesis and teratogenesis. New York: Raven Press, 1981:419-28. 